\title{
Experimental Study on the Friction Performance of Nylon - High Strength Steel Sliding Friction Pairs
}

\author{
WANG Xiao Yan \\ Wuhan institute of technology textile clothing college \\ Wuhan, China \\ xyw22@126.com
}

\begin{abstract}
In this paper, high-strength steels (yield strength greater than $900 \mathrm{MPa}$ ) paired with nylon sliders were tested on static friction coefficient. The test samples are in discshaped friction pair structure. A specific axial load is applied to the friction pair to produce a certain degree of axial pressure. The test equipment selects friction material testing machine. With the initial establishment of a nylon - highstrength steel friction performance test database, and systematic in-depth analysis of the influence mechanism of the inter-material friction performance by load, material and lubrication method. The friction coefficient decreases when the stress increases. The friction coefficient of PAM toughened nylon and POM reinforced nylon with high strength steel shows small changes along with the stress changes, while the friction coefficient of MC nylon with high strength steel shows larger changes along with the stress changes. Providing accurate data support for optimal design of the friction pair structure and material selection as well as the force calculation of friction pairs in contact with hazardous areas.
\end{abstract}

Keywords- friction coefficient; nylon sliders; friction test; contact; high-strength steel

\section{INTRODUCTION}

The nylon material has good strength, hardness and toughness, as well as light specific weight, good wear resistance It is more and more applied in sliding friction pairs in mechanical products ${ }^{[1] \sim[4]}$.

For the friction pair, the friction force directly affects the work performance. Due to the complex factors affecting friction properties, it is difficult to obtain valid data directly from theory. So by experimental tests, caring out research on influencing factors and regularity in changes of coefficient of friction between nylon and steel bears great significance ${ }^{[5] \sim[9]}$.

\section{FRICTION TEST METHODS}

\section{A. Test principle}

The test samples are in disc-shaped friction pair structure. A specific axial load is applied to the friction pair to produce a certain degree of axial pressure. And in the circumferential direction, tangential friction force is gradually applied to form friction torque. When the tangential force is increased to a certain extent, the sample occurs the tendency of relative movement, the coefficient of static friction is obtained by measuring the critical static friction torque between the friction pair samples. The calculation method is shown in Equation 1.

$$
\mu=\frac{\mathrm{M}_{i}}{\mathrm{P} \times \mathrm{R}}
$$

Wherein: $\mu$ - the static friction coefficient between the materials;

Mi- the critical torque value of friction pair in relative motion;

$\mathrm{P}$ - positive pressure acting on the friction pair interface;

$\mathrm{R}$ - average radius inside and outside the ring specimen.

\section{B. Test equipment and samples}

The test equipment selects MTS858 friction material testing machine (Fig. 1), which has excellent automatic loading, pressure retaining and real-time data collection and display functions. The sample materials include special cast nylon of three different kinds of materials, i.e. PAM toughened nylon, POM reinforced nylon and MC nylon. And its corresponding friction material is high strength steel rough surface plate. The size structure and specification requirements of the sample friction pair is shown in Fig. 2. The high-strength steel specimen through a dedicated fixture and nylon specimens was clamped in MTS testing machine on the upper and lower ends, meeting the friction dual realization testing requirements. 


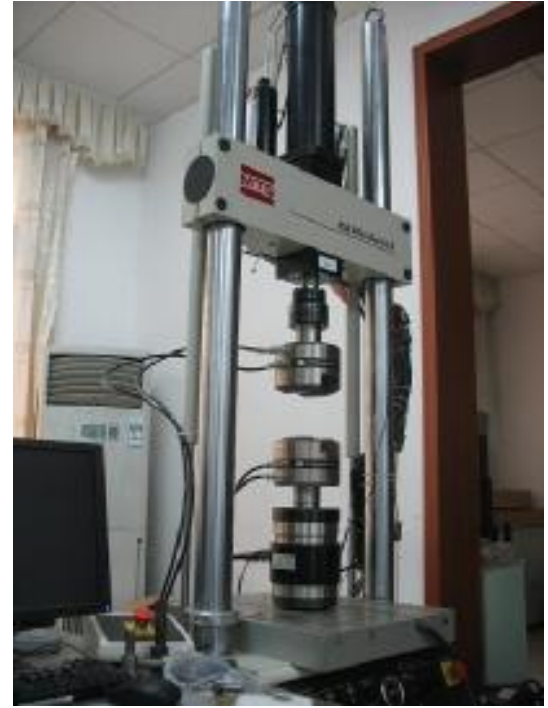

Figure 1. MTS858 material testing machine

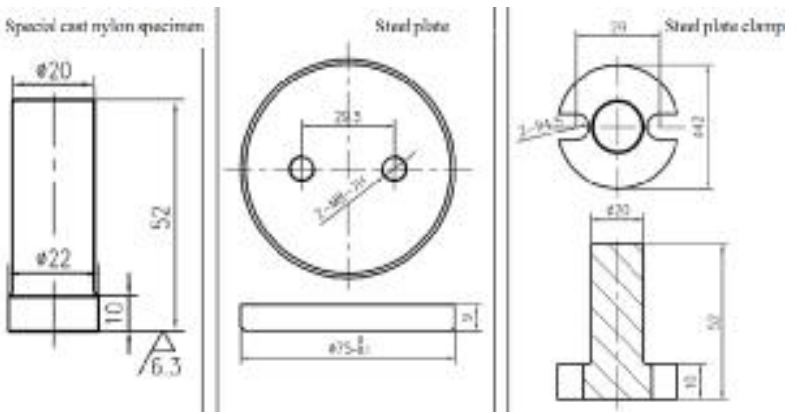

Figure 2. Schematic of dual sample processing

\section{Test conditions and working conditions}

The static friction coefficient is related to the materials' nature, finish, load levels, lubrication, temperature and static contact time and other factors [10]. The effects of static contact time is ignored. The surface finish of the dual materials is consistent with the actual contact state. Lubrication is divided into dry friction and grease lubrication. The friction coupling axial pressure level is set to $20 \sim 55 \mathrm{MPa}$, at 8 levels, with each level interval at $5 \mathrm{MPa}$.

During the test, the temperature of the friction pair is always controlled at about room temperature $25{ }^{\circ} \mathrm{C}$. The dual specimen is held in the test machine. When the tested piece is pressurized to a predetermined pressure value, the tangential force is increased gradually to set the pair in clockwise rotation so as to create relative motion, along with repetitive movements so that the pair completes three rotations at a predetermined angle, while recording the process data in real-time; the pair is to be repeated in the above process in counterclockwise rotation, while recording the whole process data (as shown in Figure 3), in order to obtain the sample's three critical static torques data clockwise and all counterclockwise. That completes a test cycle. Extract process data's six peak values to calculate the average of the absolute value which is the static torque of the material in this application. Then use the formula 1 to calculate the material's static friction coefficient.

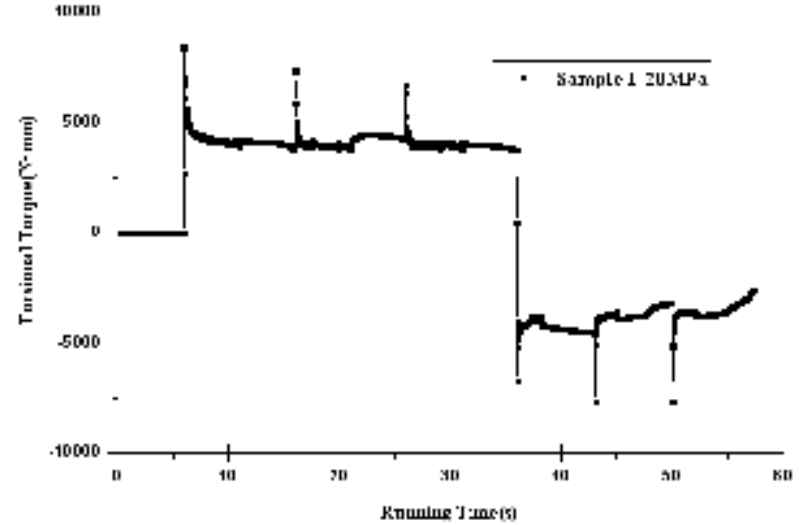

Figure 3. Test load time domain curve

\section{TEST RESULTS AND ANALYSIS}

\section{A. Influence of normal pressure}

Normal pressure between the materials has significant impact on the friction coefficient. The paper carries out finite element analysis of a certain model of machine's contact problems. The test program is determined to set normal pressure within the range of $20 \sim 55 \mathrm{MPa}$.

Fig.4 shows three nylon sliders and high-strength steel friction pairs friction coefficient curve. It can be seen from the figure the friction coefficient decreases when the stress increases. This is because when the normal pressure increases, the actual friction contact surface area increases, according to Coulomb's law, the friction coefficient becomes smaller.

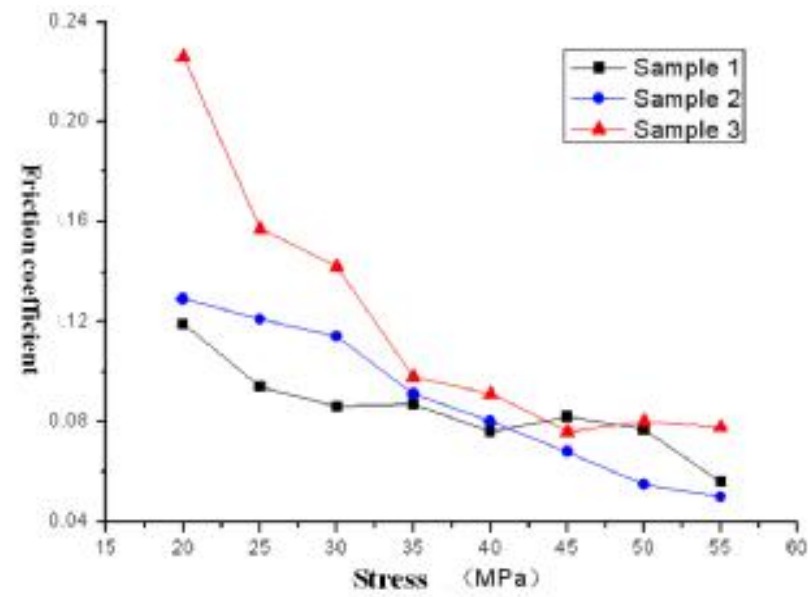

Figure 4. Sample friction coefficient curve

\section{B. IMaterial influence}

This paper has completed three kinds of nylon-high strength steel friction pairs testing, each material were tested in six groups of specimens, each specimen completed six rotation and reverse rotation tests. The three curves in Figure 4 are the results of statistical average according to the test data. The detailed data as shown in table 1 . 
TABLE I. Material Capability

\begin{tabular}{|c|c|c|c|c|}
\hline $\begin{array}{c}\text { specimen } \\
\text { s }\end{array}$ & $\begin{array}{c}\text { yield } \\
\text { strength } \\
(\mathrm{MPa})\end{array}$ & $\begin{array}{c}\text { Tensile } \\
\text { strength } \\
(\mathrm{MPa})\end{array}$ & $\begin{array}{c}\text { modulus } \\
\text { of } \\
\text { elasticity } \\
(\mathrm{MPa})\end{array}$ & $\begin{array}{c}\text { extensi } \\
\text { bility } \\
(\%)\end{array}$ \\
\hline $\mathrm{N}-1$ & 75 & 81 & 3331 & 35 \\
\hline $\mathrm{N}-2$ & 81 & 85 & 3159 & 30 \\
\hline $\mathrm{N}-3$ & 80 & 80 & 3294 & 30 \\
\hline $\mathrm{N}-4$ & 79 & 79 & 3227 & 15 \\
\hline $\mathrm{N}-5$ & 86 & 86 & 3217 & 28 \\
\hline $\mathrm{N}-6$ & 86 & 86 & 3262 & 28 \\
\hline $\mathrm{N}-7$ & 80 & 80 & 3341 & 28 \\
\hline $\mathrm{N}-8$ & 83 & 83 & 3331 & 27 \\
\hline $\mathrm{N}-9$ & 85 & 85 & 3440 & 39 \\
\hline N-10 & 87 & 87 & 3276 & 35 \\
\hline average & 82.2 & 83.2 & 3287.8 & 29.5 \\
\hline
\end{tabular}

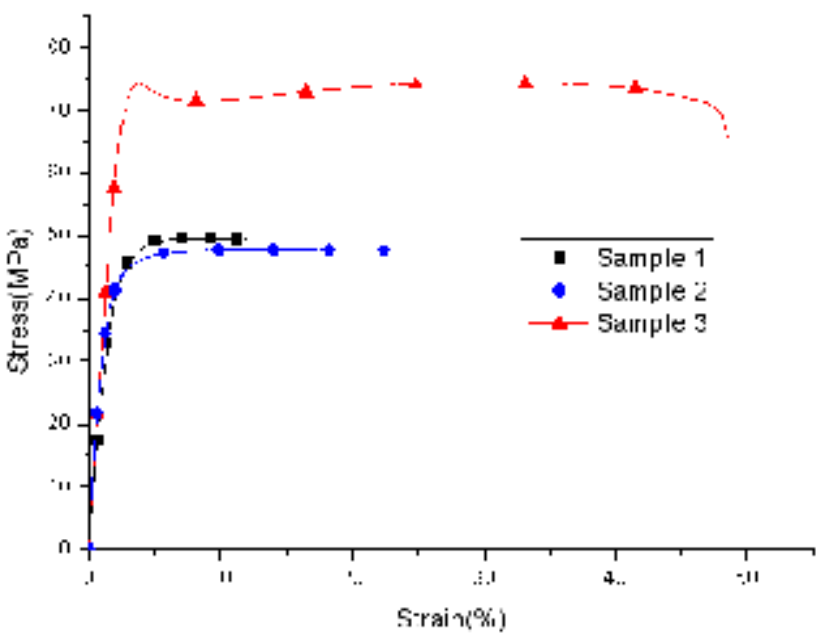

Figure 5 is the tensile test results of the three materials. From Fig.5, the maximum strength of MC nylon, PAM toughened nylon and POM reinforced nylon is similar. Test data of material with different pressure are shown in table 2 .

\begin{tabular}{|c|c|c|c|c|c|c|}
\hline $\begin{array}{c}\mathrm{M} \\
\mathrm{A} \\
\mathrm{T}\end{array}$ & $\begin{array}{l}\text { Press } \\
\text {-ure }\end{array}$ & test 1 & test 2 & test 3 & test 4 & test 5 \\
\hline \multirow{8}{*}{$\begin{array}{l}\mathrm{P} \\
\mathrm{A} \\
\mathrm{M}\end{array}$} & 20 & 0.081 & 0.096 & 0.119 & 0.158 & 0.126 \\
\hline & 25 & 0.093 & 0.089 & 0.083 & 0.117 & 0.106 \\
\hline & 30 & 0.076 & 0.071 & 0.076 & 0.107 & 0.094 \\
\hline & 35 & 0.093 & 0.091 & 0.079 & 0.105 & 0.096 \\
\hline & 40 & 0.059 & 0.063 & 0.074 & 0.082 & 0.075 \\
\hline & 45 & 0.065 & 0.069 & 0.077 & 0.091 & 0.082 \\
\hline & 50 & 0.084 & 0.080 & 0.078 & 0.098 & 0.070 \\
\hline & 55 & 0.041 & 0.047 & 0.053 & 0.055 & 0.055 \\
\hline \multirow{7}{*}{$\begin{array}{l}\mathrm{M} \\
\mathrm{C}\end{array}$} & 20 & 0.128 & 0.167 & 0.212 & 0.301 & 0.236 \\
\hline & 25 & 0.114 & 0.134 & 0.169 & 0.201 & 0.149 \\
\hline & 30 & 0.172 & 0.155 & 0.151 & 0.171 & 0.146 \\
\hline & 35 & 0.077 & 0.092 & 0.086 & 0.113 & 0.100 \\
\hline & 40 & 0.081 & 0.090 & 0.090 & 0.124 & 0.097 \\
\hline & 45 & 0.071 & 0.068 & 0.073 & 0.105 & 0.078 \\
\hline & 50 & 0.071 & 0.074 & 0.085 & 0.101 & 0.076 \\
\hline
\end{tabular}

\begin{tabular}{|l|l|l|l|l|l|l|}
\hline & 55 & 0.087 & 0.074 & 0.083 & 0.092 & 0.077 \\
\hline \multirow{4}{*}{$\mathrm{P}$} & 20 & 0.172 & 0.137 & 0.136 & 0.160 & 0.122 \\
\cline { 2 - 7 } & 25 & 0.120 & 0.112 & 0.132 & 0.138 & 0.119 \\
\cline { 2 - 7 } $\mathrm{O}$ & 30 & 0.115 & 0.112 & 0.100 & 0.129 & 0.121 \\
\cline { 2 - 7 } $\mathrm{M}$ & 35 & 0.085 & 0.071 & 0.087 & 0.105 & 0.100 \\
\cline { 2 - 7 } & 40 & 0.075 & 0.067 & 0.079 & 0.089 & 0.092 \\
\cline { 2 - 7 } & 45 & 0.068 & 0.053 & 0.064 & 0.075 & 0.074 \\
\cline { 2 - 7 } & 50 & 0.058 & 0.050 & 0.052 & 0.066 & 0.060 \\
\cline { 2 - 7 } & 55 & 0.053 & 0.049 & 0.044 & 0.056 & 0.051 \\
\hline
\end{tabular}

From Fig.4, the friction coefficient of PAM toughened nylon and POM reinforced nylon with high strength steel shows small changes along with the stress changes, while the friction coefficient of MC nylon with high strength steel shows larger changes along with the stress changes. The reason is that when the stress reaches about $50 \mathrm{MPa}$, PAM toughened nylon and POM reinforced nylon are plastically deformed, The actual contact area increases, resulting in reduced friction coefficient. However, PAM toughened nylon and POM reinforced nylon friction coefficient curves cross at $40 \mathrm{MPa}$. Smaller the stress, larger the POM reinforced nylon friction coefficient; larger the stress, larger the friction coefficient of PAM toughened nylon, because PAM toughened nylon is stronger than POM reinforced nylon, after plastic deformation, POM reinforced nylon's deformation is greater than the PAM toughened nylon. The actual contact area is slightly larger, therefore, the friction coefficient is smaller.

\section{Surface roughness influence}

Figure 6 shows three groups of MC nylon - high strength steel friction pairs specimen friction coefficient curves under different lubrication conditions It is evident from the figure that the friction coefficient when lubricated is far below the data in case of dry friction. The data shown in the picutre under each load level are relatively concentrated, without significant dispersion, the error is within $6.3 \%$, and with the increase of stress, the friction coefficient values tend to converge.

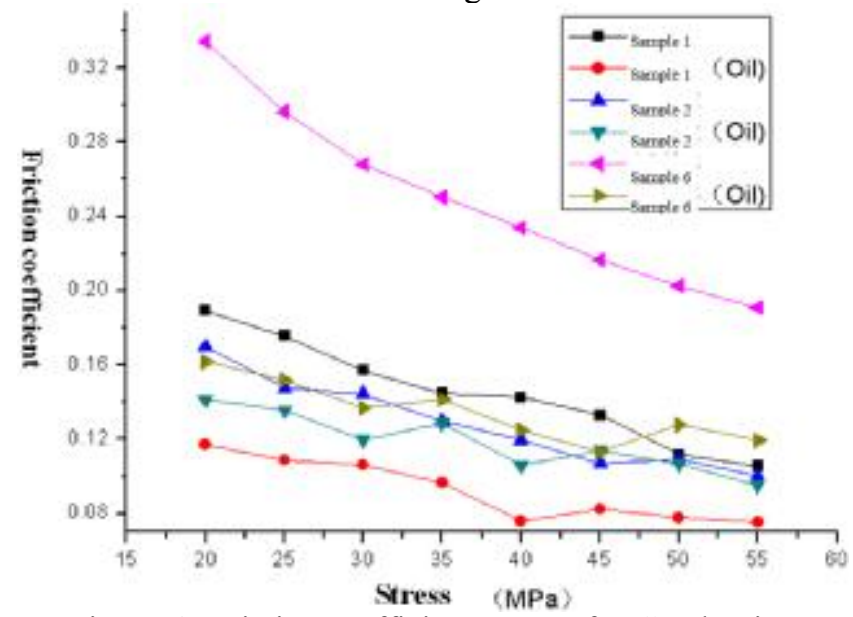

Figure 6. Friction coefficient curve of MC nylon in different lubrication conditions

\section{CONCLUSION}

Three kinds of nylon material with high strength steel static friction coefficient test is completed on the MTS testing machine. The method utilized the test principle of 
static friction coefficient and the torsion test functions of the material testing machine, accurately tested nylon high strength steel friction pair static friction coefficient.

From the analysis of experimental data, material's friction coefficient is closely related to the material, stress, surface roughness and other factors. That's why the sliding friction pair design should make reasonable choices of the nylon material, optimize the structure and layout of nylon components to reduce the adverse effects caused by friction.

\section{REFERENCES}

[1] Wang Weizu and Huang Ping, "Researc on stribeck curves in different surface roughness under friction pair lubrication condition.," Friction Journal, vol. 24, 2004, pp. 254 - 257

[2] Wen Shizhu, Friction principles.,Tsinghua University Press, 1990, Beijing

[3] Han Jianfei, "MC nylon slider friction coefficient tests and analysis," Technological innovation Herald, vol. 9, 2008, pp. 73-74
[4] Chen Chuanzhi and Cui Dongfang," Influencing factors on friction coefficient of nylon material containing oil," Railway technical supervision, vol. 12, 2005, pp. 9-11

[5] Sun Shihao and Xiang Dinghan, "Development and application of bridge fabrication machine heavy-duty self-lubricating sliders," Railway Standard Design, vol. 12, 2008, pp. 45-47

[6] Teng Bing and Wang Shi bo, "Friction contact model and experimental investigation of MC nylon composite under face - on - face torsion”, Friction Journal, vol. 34, 2014, pp. 73 - 78

[7] Zhang zhao zhu, Xue qun ji, Liu wei min, Shen wei-chang, "Effects of oil additives on friction and wear properties of MC nylon," Friction Journal, vol. 240, 2000, pp. 472 - 474

[8] Gallego L, Nélias D, Deyber S. , "A fast and efficient contact algorithm for fretting problems applied to fretting mode I, II and III”, Wear, vol. 2010, pp. 208-222.

[9] C. Ren, H. L. Pan. , “An analysis of inclusion defects on strip steel surface induced bypolyurethane roller", Engineering Failure Analysis, vol.18, 2011, pp. 1122-1127

[10] Zhang Wenlan and Zhang Changming, "Static friction coefficient of elastic contact between cylindrical and rigid planes," Mechanical Management and Development, vol. 5, 2011,pp. 91-94 